\title{
Evaluation of an early discharge from hospital scheme focussing on patients' housing needs: The ASSIST Project
}

\begin{abstract}
A bstract
This study calculated a return on investment of an early discharge from hospital scheme focussing on im proved responses to patients' housing needs. The study identified critical success factors of the scheme that will inform potential spread of the intervention to other localities.

Financial return on investment based on service costs and benefits were calculated and the critical success factors were identified through interviews with key stakeholders. The annualised return on investment of the scheme was $£ 3.03$ for each $£ 1$ invested. Close working relationships between health and housing and aspects of the local housing stock (such as direct local control) were key to realising the return on investment.
\end{abstract}

Keywords: delayed discharge, health, housing, local government, NHS, social care.

What is known about this topic:

1. Delayed discharges of m edically-stable patients from hospitals affects both the efficiency and effectiveness of patient clinical treatment, and the cost effectiveness and financial sustainability of acute hospital providers.

2. One specific cause of delayed discharges, is changes in patients' housing needs requiring rehousing, adaptations to existing or potential homes and/or co ordination with aftercare services not being $m$ et in a tim ely $m$ anner.

3. Im provements in the effectiveness of local health and social care systems is one of key drivers in tackling delayed discharges.

What this paperadds: 
1. The annualised return on investment of the housing scheme evaluated was $£ 3.03$ for each $£ 1$ invested (303.3\%).

2. Close working relationships between health and housing and aspects of the local housing stock (such as direct local control) are key to realising the return on investment.

\section{Introduction}

Delayed discharges of m edically-stable patients from hospitals is a perennial issue for the health and care system. This issue is a significant and increasing problem for individual hospitals and for the UK National Health Service (NHS) as a whole. It directly affects both the efficiency and effectiveness of patient clinical treatment, and the cost effectiveness and financial sustainability of the NHS.

In May 2016, the National Audit Office (National Audit Office, 2016) published its latest report on this issue entitled 'Discharging older patients from hospital'. It noted that the num ber of days in hospitals when beds a re occupied by patients, who should have been discharged, has increased by $31 \%$ over the last two years to $1.15 \mathrm{~m}$ illion days. This does not include patients receiving non-acute treatment. The NAO report suggests that the figure could be as high as 2.7 million days, if non-acute treatment delays a re included.

In its 2018 report on integrated care, the Health and Social Care Select Committee of the House of Commons recommended that the law needed to change to move to a more integrated, collaborative and place-based approach to health and care (Health and Social Care Committee 2018). This has recently been followed by the committee's report on the governments' subsequent proposals for legislative change to give effect to this strategic intention (Health and Social Care Committee 2019). These proposals are intended to prom ote collaboration and lessen competition within the NHS. They also call for the Department of Health and Social Care, NHS England and NHS Improvement to be clearer about the input and roles local government, the voluntary and wider community sector 
as well as independent providers, are expected to have in the future of the NHS (2019p 3).

This paper reports the results of an intervention that targets one specific cause of delayed discharges, namely delays due to patients' changing housing needs not being expedited. The rationale is that some delayed discharges could potentially be reduced if, post-release from hospital, suitable housing accommodation and/or a rrangements were in place in advance of the patient discharge date. This constitutes one component of the delayed discharges problem but it is perhaps sym ptomatic of the seemingly slow progress to integrated working between health and social care (National Audit Office, 2016). Im provements in the effectiveness of local health and social care systems is one of the key drivers in tackling delayed discharges according to the NAO report. At the same time, commissioners need evidence on the cost-effectiveness of interventions that require joint funding. The research reported here explored the return on investment of a joint health, social care and housing initiative focussing on early identification of housing needs, and then taking (usually low-cost) rem edial action to address those needs.

There is a body of reasonably robust evidence that shows, in general, that m ajor and $m$ inor adaptations to the homes are cost effective and improve the health and wellbeing of older people (Powell et al., 2017). In addition, there is evidence from practice that joint working between health and housing can reduce delays in hospital discharge (Jones, 2017). The study reported here adds to that literature. Im portantly, we identify the critical success factors that need to be considered in orderfor the innovation to have a high probability of success if transferred to other localities.

The setting for this pilot early discharge intervention scheme is Mansfield, UK. Mansfield is the largest urban area in Nottinghamshire, outside Nottingham City with a population of approximately 107,000 . According to Public Health England statistics, it is one of the most deprived local a uthority areas in England (Public Health England, 2017). The health 
of people in Mansfield is worse than the English average, and the life expectancy for both men and wom en is lower than the English average. Those aged 65-84 represent $16.2 \%$ of the population of Mansfield and data from the 2011 census indicate that $59 \%$ of that age group had a lim iting long-term illness (Nottingham Insight, 2011). This level is the highest in the County of Nottingham shire and significantly higher than the East Midlands regional and national averages at 48.9 and $47.2 \%$, respectively.

The ASSIST discharge project was established in Mansfield in 2014. ASSIST is the acronym for the Advocacy, Sustainment, Supporting Independence and Safeguarding Team at Mansfield District Council (DC). It is a scheme established to support the early discharge and immediate residential care of patients from the main hospital providerin the area, King's Mill Hospital in the Mansfield/Sutton-in-Ashfield conurbation. The scheme receives clients from health, housing and social care partners in central Nottinghamshire as well as occasional ad-hoc referrals. Although initially focussed on Mansfield DC administrative area, it also co-operates with some of the equivalent services in the adjoining administrative area of Ashfield DC.

The ASSIST service aims a re to:

- Prevent avoidable homelessness amongst this particularly vulnerable group

- Support tenants to rem ain adequately housed

- Reduce or prevent avoidable or elongated admissions to hospital or residential care

- Expedite discharges from the Kings Mill Hospital (both Em ergency Department (ED) and ward discharges), and from residential care in Mansfield.

Operationally, it focuses on the early identification and assessment of patients potentially needing housing services who have presented for treatm ent at King's Mill Hospital either through the em ergency department or elective care on a specialist or generalist ward. 
On establishing a future potential need for a housing service, the full range of housing services and advice that the housing a uthority can provide, are expedited to facilitate early discharge and the freeing up of bed spaces at the hospital. This ensures unnecessary stays within King's Mill Hospital for patients are reduced and ward capacity is increased for patients waiting to be treated. Housing services includes, but are not lim ited to, re-housing of clients in m ore appropriate accommodation, or major or m inor adaptations to the patients' current accommodation (or proposed accommodation), or advice guidance on benefits and other services.

The research team was commissioned with a very lim ited budget to undertake a form al evaluation of the ASSIST scheme to record and demonstrate activity and outcomes, and to assess actual and potential savings. An opinion was also sought as to whether development and/or continuation of the scheme were considered to be replicable, scalable or portable to other locations. The ASSIST team were engaged in providing a variety of services and other activities both for the Mansfield DC and other stakeholders but for the purpose of this evaluation we refer to the early discharge project as the ASSIST project.

\section{Methods}

The evaluation was conducted as a financial return on investment (RoI). It is possible to provide either an appraisal based upon a financial m odel essentially calculating the financial return on investment, or one based upon a calculation of the social return on investment (Nicholls et al., 2012), although the latter is more resource intensive. In this case, it was not possible, given the inherent time, information and resource constraints, to com plete a coherent and realistic assessment of the full social returns on investment. This research is primarily based upon a financial calculation of costs and benefits across the principal health and social care organisations involved (with some acknowledged assumptions about impacts). It is however, accompanied by comments on some of the

wider long-term impacts that should be considered. The overall approach of the work 
was exploratory in nature and did not incorporate any experimental (e.g randomised controlled trial) or observational study (e.g. case-control or controlled cohort) design. Because of the practical constraints it was also im possible for it to take into account the non-monetary benefits of the interventions or to calculate the opportunity costs of providing the services.

The research had three distinct phases: 1 . Pilot evaluation; 2 . RoI calculation, based on 10 m onths of data collection; and 3. Im pacts of ASSIST beyond the principal acute healthcare facility.

\section{Phase 1: Pilot evaluation}

Firstly, we developed the data collection m ethods and became familiar with the ASSIST scheme in practice. This involved the following activities:

a) Initial fact-finding phase. This involved interviews and m eetings with senior staff at Mansfield DC.

b) Determining the mechanics of the system so that an appropriate appraisal could be identified and designed. This involved the shadowing of the Homeless Prevention Officer, whilst undertaking herduties at the King's Mill site. This illuminated the issues and the m ethodologies she used to achieve solutions for patients who needed housing assistance and who fell within the parameters of the scheme. This exercise was undertaken for a day. During the course of this visit contact was made with various stakeholders and opportunities were taken for interviews to take place.

c) Further interviews and focus groups were undertaken with staff involved in the project from Mansfield DC. In total 16 m embers of staff from Mansfield DC and 12 from King's Mill Hospital took part in the study. The focus groups and interviews were designed to explore the practicalities of the scheme and the perceived benefits in qualitative terms. Although the qualitative benefits are not the focus of the study it was necessary to verify this aspect and corroborate the case studies produced by Mansfield DC staff to ensure validity of the interventions made. 
The study participants included:

- managers from the two main stakeholder organisations $(n=4)$

- those involved in delivering the scheme $(n=12)$ - employees of the Housing Services in Mansfield DC including housing services $m$ anagers and a $m$ ental health specialist

- health and social care professionals $(n=9)$, and

- finance staff from stakeholder organisations ( $n=3$ : Commissioning body, King's Mill Hospital, and Mansfield District Council).

d) Examination of records of interventions made. This examination was undertaken by staff from Mansfield DC and the research team. Judgements were $\mathrm{m}$ ade based upon evidence of the effectiveness of interventions as to the potential benefits to the discharge process. In this pilot phase of the project, all ASSIST interventions were examined from the start of the scheme in 2014 , however, the two most representative and appropriate m onths (March and April, 2015) were scrutinised in detail. This was after the initial set-up period it was determined that the scheme was working effectively. These particular m onths were also those which had the most detailed and reliable data. From these data sets the savings in term s of in-patient days were determined and these were used to calculate the savings from the scheme.

e) The interventions that were provided included in-homeservices, such as the installation of lifelines, sensors, key safes, and m inor adaptions. Provision of new homes by prioritising adapted accom modation for high dependency clients, fast tracking repairs to expedite discharge and early identification of m ore suitable/appropriate accommodation together with expediting support services whether in previous or new hom es. This later included providing specialist support such as welfare and domestic violence; accessing food banks, furniture 
projects, and help with applications or claim s such as benefits and home finder applications.

f) As part of the evaluation an assessment panel was e stablished, chaired by NTU but consisting of managerial representatives from the NHS (commissioning, secondary, primary and m ental trusts), local authorities (including social care, housing and benefits managers with collective knowledge of the services and support available in all patient or client geographical areas affected) welfare and voluntary agencies and advisers from the crim inal justice system. These assessment panels were supported by system analysts and accounting expertise for all four sectors, as the accounting systems varied across the sectors. The panel calculated what the costs were with the ASSIST service and what the costs would have been without the service being available. This varied according to the level of services housing, welfare and social services being available in different local a uthority areas. The panel also identified types of cases that were replicable and therefore agreed a cost percase to be applied consistently together with cases (usually complex and multi-faceted) that required an individual specific appraisal.

g) Calculation of an initial estimate of the R eturn on Investment. The calculated RoI, had of necessity to make a num ber of assumptions relating to tariffs, costings and benefits. Wherever there were assumptions to be made the assessment team took a cautious approach assuming the m aximum of potential costs and the m inimums for potential benefits. The estimated RoI was $£ 1.34$ for each $£ 1$ invested. On this basis we proceeded to the second $\mathrm{m}$ ain stage of the research, described below.

\section{Phase 2: RoI calculation}

In the second majorphase of the project we examined a longerperiod of data when the scheme was operating at a more mature stage of development, and at a highercapacity than in the pilot phase. The m ethods for data collection followed the same m ethods used 
in the pilot phase described above. Data collection was from July 2015 to April 2016. The form ula used was ROI = ( (benefits - costs of scheme) / costs of scheme) $\times 100$ (Stone, 2005). A one-way sensitivity analysis was conducted by simply m ultiplying the full year benefits by a range of multipliers $(0.6,0.7,0.8$ and 0.9$)$ to give estimates of the lower bound on the RoI.

The financial calculations were based upon the Clinical Commissioning Group charge rates for excess bed days on a Health Resource Group (HRG) basis. This mean charge per day of $£ 225$ was confirm ed by senior staff from the finance function at the King's Mill Hospital before being adopted.

The costs of the Scheme to Mansfield DC have been provided and ratified by m embers of the Council's finance function. They were contained within the annual revenue budget based upon Chartered Institute of Public finance and Accountancy guidance, and were internally and externally audited, although they are not shown as separate identifiable allocations in the final accounts. The evaluators, the finance specialists and housing specialists from the authority, were of the view that, in term s of the cost of housing stock, there is no marginal cost as the scheme, in term s of the use of housing stock, is a prioritisation issue and therefore no additional cost. It is im portant to note that the staff and resources for the ASSIST scheme were already in place in the Local Authority and hence we have not included these as start up or setup costs in the costs element of the RoI calculation. Therefore, the $\mathrm{R}$ oI reflects the potential of integrated service delivery that is possible when local authority services can effectively work with NHS services and have access to these resources. There were some initial m anagement costs in both sectors to facilitate this joint working but these were considered to be $\mathrm{m}$ inimal by both the Local Authority and the hospital and were subsumed within day to day change costs of their respective operational budgets. As m entioned above however, this did not allow the calculation of a true opportunity cost comparison. 
All savings and costs have been calculated on the most prudent options, therefore, all savings were believed, by the investigators to be conservative; for example a cap was put on the most complex cases at 30 days, and in extreme cases at 60 days.

\section{Phase 3: Wider impacts of ASSIST}

The third and final stage of the research considered the wider im pacts of the ASSIST scheme. This information was collected from stakeholder interviews and documented feedback on the ASSIST scheme. This included input from staff in Social Services delivering the Scheme and service users, as well as initial considerations from m ental health services and the crim inal justice service.

\section{Findings}

Data from 1127 admissions and their subsequent use of ASSIST was utilised.

Return on investment

Table 1 presents the system savings based on reduced acute bed days. The total bed savings between from July 2015 to April 2016 have been linearly extrapolated to give full-year effects.

$============$ Table 1 about here

The annual cost of the service to Mansfield DC was $£ 340,000$, (although the inyear revenue cost appeared to falling as the project matured). However, the RoI calculated for this study is $£ 3.03$ for each $£ 1$ invested. The mean bed days saved per admission was 4.5 and the mean bed days cost saving peradmission was $£ 1,013$.

The results of the sensitivity analysis are shown in Table 2.

$============$ Table 2 about here 
Wider impacts of ASSIST

On the basis of our analysis and understanding of the ASSIST scheme, it appears that the majority of savings fall within the NHS and in particular hospital provided services and by the relevant clinical commissioning groups as was determined above. We did however, consider otherbeneficiaries.

From work undertaken as part of this phase it is clear that, there are significant savings that have been made to Social Services provision, primarily to the reablement services. Utilizing agreed criteria and costs from managers in Social Services we have calculated that the annual savings to reablement services was in the region of $£ 107,000$ annualised.

We did not undertake a form al assessment of the im pact on m ental health services within the NHS. This is on the basis that any evaluation for the m ental health services is likely to result in relatively small number of cases. At this stage we can clearly anticipate that the costs and benefits are likely to be significantly lower than the equivalent figures for acute hospital services and equivalent figures for Clinical Commissioning Groups, but cannot realistically ascribe a precise or a robust figure.

It is apparent that, as the ASSIST service has developed, the range of housing services provided by the host local autho rity (Mansfield) has expanded, both as a result of changes in the hospital discharge arrangements and changes in the range and nature of services provided by Social Services. However, these costs have generally been contained and $m$ et from efficiencies in the operation of the service. 
W ithin the parameters, of tim e and sampling constraints of this study, we have not been able to assess the im pact of the ASSIST project on patients/clients of the Crim inal Justice System. This proved to be beyond the capacity, scope and time available for the current study. In the circum stances, and for the purpose of this evaluation, we have not identified the costs and benefits of the ASSIST project to the Crim inal Justice System.

It is clear that the service has m ade considerable qualitative benefits to the lives of beneficiaries of the service. This is greatly valued by the clients, theirfamilies, friends and carers. Although it can be only illustrative, the following is an anonymised quote from one recipient of the scheme:

"I arrived by taxi at my sanctuary, on arrival I was met by my support worker. She took my few possessions and carried them for me to the flat. I arrived wearing only a pair of pyjamas. She kindly showed me around the flat which was immaculate in every way. Within one week she was bringing me clothes and things I needed. Anything I was worried about, she sorted it out and put my mind at rest. The respite flat is a lifeline for vulnerable people like myself and I feel that without all the help I received I would not be here today."

It is also clear that those involved directly and indirectly in the provision of services have similarly identified considerable benefits in term s of patient care as the following quote illustrates:

"During my time with the hospital assessment team I have found the support and assistance of the (ASSIST) team invaluable whilst working on some very challenging cases. Just a quick call through to them is all that's needed to instigate extra help for some very vulnerable service users, cutting down on the need to fill out lengthy referral forms. They are flexible and quick to react - often visiting service users within the hour. They have 
a calm and down to earth approach and have an excellent rapport with staff and service users; it's clear to see why they are held in such high regard. Their essential work aids the discharge process; from preventing homelessness, providing lifelines and key safes to offering housing advice, without them many service users would be in hospital for a lot longer."

\section{Discussion}

The key findings from the evaluation are as follows:

a) There was clearevidence from observation and interviews that the scheme benefits the efficiency of hospital discharge and reduces the burden on hospital and social services staff. The return on investment was $£ 3.03$ for each $£ 1$ invested $(303.3 \%)$ but it is clearfrom in-yearcalculations that this rate of return was im proving as the project teams and integrated working im proved. A similar scheme operating in Nottingham reported a return on investment of $640 \%$ (Jones, 2017). The latter study included benefits arising to other stakeholders and not just the principal acute hospital as here.

b) The costs of providing the service are relatively fixed therefore there is a high level of gearing in term s of net savings if there is a potential increase in activity. These costs m ay also reach a step-change at some point in tim e, however, there is not sufficient data to determ ine at what level of activity this will occur.

c) Many of the interventions a re relatively low in term s of m arginal cost, but significant in the ability to enable a hospital discharge. At this stage, the longterm $\mathrm{m}$ ix of cases is not able to be determined. This is vital to any investment decision; however, the margins are such the main findings from this study are not undermined. 
d) The availability of the service, the staff's understanding of housing issues and the ability to action and expedite solutions clearly assists in the discharge process.

e) There are benefits beyond the principal acute healthcare provider, and future similar studies should aim to capture these; a social return of investment approach (Nicholls et al., 2012) or a multi-agency return on investment approach is recommended.

f) Anecdotally, it was noted that the time taken to rehouse clients from outside of the Mansfield District was consistently in excess of the tim e taken within the District.

It was apparent to the evaluators that there were a num ber of factors that were critical to the potential success of the discharge scheme, that were available in Mansfield but are not universally available in all housing authority areas. There are also a number of service configurations, patterns of deployment, inter-organisational and inter-personal relationships that have been critical to successful delivery of the pilot project that also may not be universally available.

In order to assess whether the service is scalable replicable, and/or portable, and therefore whether the commissioners (or other NHS com missioners) would be willing and able to invest in either expanding the Mansfield initiative and/or replicating it elsewhere it is necessary to:

- Identify the critical success features that make the current pilot project a success,

- Identify the critical success factors that $m$ ay be $m$ issing but could potentially be developed.

- Identify the critical success factors that a re not available and ca nnot realistically be developed. 
We consider the project benefits significantly from the following list of tangible and intangible features, which have been critical to the success of the pilot project. The tangible and non-tangible features will be subject to change over time.

- The housing services at Mansfield DC have a large and critical asset base in term s of the number and variety of housing units that it has direct control over, and the speed with which it can facilitate rehousing or dwelling adaptation. Mansfield DC did not form an Arm s-Length Management Organisation (ALMO) nor outsource its dwelling stock. It has experienced relatively low dem and under right to buy. These features are not unique but are now relatively rare among housing authorities particularly district councils.

- Mansfield DC has also retained a directly controlled, Direct Labour Organisation (DLO) with a range of appropriate building skills and experience to m aintain and adapt dwellings. This a gain is not unique but is now also rare among housing authorities particularly district councils. These two features (retention of a large variable dwelling stock and the retention of a DLO) can and do occasionally coincide.

- The level of voids and turnover of tenancies within the current housing service allows capacity and services to be flexible, responsive and where appropriate bespoke to the individual tenant. Mansfield DC administrative area has a single large town at its centre with a full range of services and is relatively compact with relatively low travel costs, and potentially rapid response capability.

- King's Mill Hospital is strategically located (relative to both Mansfield and Ashfield District Councils administrative area and to Mansfield and Ashfield CCG's administrative area) and its catchment area, while not coterm in ous, facilitates collaboration.

- The relationship and integrated working with private landlords, and those non profit and charitable services supporting vulnerable groups. 
- The citizen centred culture of the prim ary provider organisation (Mansfield DC) and the sophisticated professional appreciation of the potential contribution of housing and related services to m eeting wider social and economic objectives as well and particularly public health objectives.

- The human resources available to in term s of qualified experienced housing professionals and professionals experienced in supporting vulnerable groups such as the homeless, vulnerable elderly, alcohol and drug dependent, and those in need of mental health services.

- Dwelling a vailability and land supply for new dwellings means the private housebuilding industry is unlikely to compete vigorously for this part of the market.

One interviewee expressed the view that this as a 'perfect storm' of circum stances, which has enabled the pilot project to work synergistically with the circum stances of both the host population; the various service provider's com munities of interests and the resources, skills and experience available to the collaborating partners. This m ultivariate synchronicity clearly arises from a co mbination of the features identified.

The exact determination as to which com bination of factors are necessary; which individual factors a re necessary but not sufficient; and which individual factors (if not currently available) can realistically be developed, is a m atter that needs further investigation, but there is little doubt that they have all contributed to the positive outputs and outcomes being achieved by the pilot project.

This research is subject to obvious limitations. Primarily, the evaluation is without a matched control group or control setting. However, it is em phasised that the return of investment was calculated using relatively conservative estimates of bed days saved by the intervention. 
The link between poor housing and poor health has been long established. O ne estimate has put the cost of poor housing to the NHS at $£ 1.4$ billion peryear (BRE 2015). For decades the 'silo' arrangements of health and local government (including social care and housing) have hindered joint working on schemes such as ASSIST that will costeffectively reduce that burden. There are opportunities now through sustainability and transformation partnerships and integrated care systems (NHS England 2018, Health and Social Care Committee 2018, 2019) for the key actors to work together and meet this challenge.

Finally, there are limitations with the current study. Wider benefits of the scheme beyond the principal a cute hospital a re noted but not fully quantified. It is likely that a full social return on investment, inter alia. would capture further m onetary and nonm onetary benefits, but this was beyond the scope and resources of this study. Secondly, the study did not follow-up patients to identify readmissions to hospital or transfers of patients to home care settings. These would have had the effect of reducing the benefits of the scheme.

\section{Conclusions}

The evidence from this evaluation suggests that there is a clear service and financial benefits of the ASSIST scheme. Close working relationships between health and housing and aspects of the local housing stock are key to the success of this initiative, and for the scheme to be considered replicable to otherareas. 


\section{References}

BRE (2015). The cost of poor housing to the NHS [online]. Available at:

www.bre.co.uk/healthbriefings (Accessed 2 January 2019).

Health and Social Care Committee, (2018) Integrated care: organisations, partnerships and systems, Seventh report of Session 2017-19, HC 650.

Health and Social Care Committee, (2019) NHS Long-term Plan: legislative proposals Fifteenth report of Session 2017-19, HC 2000.

Jones, A. (2017). Housing to Health [online]. Available at https://nottinghamcityhomes.org.uk/EasySiteWeb/GatewayLink.aspx?alId=5700 (Accessed 2 January 2019).

National Audit office (2016). Discharging older patients from hospital [online]. Available at https://www.nao.org.uk/report/discharging-older-patients-from-hospital/ (Accessed 2 January 2019). ISBN: 9781786040527.

NHS England (2018). Refreshing NHS plans for 2018/19 [online]. Available at:

www.england.nhs.uk/publication/refreshing-nhs-plans-for-2018-19/ (Accessed 2 January 2019).

Nicholls, J., Lawlor, E., Neitzert, E. and Goodspeed, T. (2012). A Guide to Social Return on Investment. The SORI Network. [Online].

http://www.socialvalueuk.org/app/uploads/2016/03/The \%20Guide\%20to \%20Social\% 20 Return\%20on\%20Investment\%202015.pdf(Accessed 2 January 2019). ISBN: 978-09562274-0-9. 
Notting ham Insight (2011). Census 2011 Limiting -long-term-illness with age breakdowns [online]. Available at https://www.nottingham insight.org.uk/DocumentLibrary/Document-Library/185545 (Accessed 2 January 2019).

Powell, J., Mackintosh, S., Bird, E., Ige, J., Garrett, H. and Roys, M. (2017). The role of home adaptations in im proving later life [online]. Available at https://www.ageing better.org.uk/sites/default/files/2017-

12/The $\% 20$ role $\% 20$ of $\% 20$ home $\% 20$ adaptations $\% 2$ in $\% 20$ improving $\% 20$ later $\% 20$ life.p df (Accessed 2 January 2019).

Public Health England (2017). Mansfield District Hea Ith Profile 2017 [online]. Available at http://fingertipsreports.phe.org.uk/health -profiles/2017/e07000174.pdf (Accessed 2 January 2019).

Stone, P.W. (2005). Return-on-investment m odels. Applied Nursing Research 18, $186-$ 189. DOI: $10.1016 /$ j.apnr.2005.05.003. 


\section{Tables}

\begin{tabular}{|c|c|c|c|}
\cline { 2 - 4 } \multicolumn{1}{c|}{} & Admissions & $\begin{array}{c}\text { Number } \\
\text { of bed } \\
\text { days } \\
\text { saved }\end{array}$ & $\begin{array}{c}\text { Mean } \\
\text { cost of } \\
\text { bed day } \\
\text { in } \\
\text { hospital }\end{array}$ \\
\hline Total & 1127 & 5078 & $£ 225$ \\
\hline
\end{tabular}

\begin{tabular}{|c|c|}
$\begin{array}{c}\text { Bed Day } \\
\text { Savings } \\
\text { July } 15- \\
\text { Apr } 16\end{array}$ & $\begin{array}{c}\text { Full Year } \\
\text { Effect }\end{array}$ \\
\hline$£ 1,142,550$ & $£ 1,371,060$ \\
\end{tabular}

Table 1 . System savings based on reduced acute bed days

\begin{tabular}{|c|c|}
\hline $\begin{array}{c}\text { Sensitivity analysis multiplier } \\
\text { (applied to full-year benefits) }\end{array}$ & Rol (\%) \\
\hline 0.6 & 142.0 \\
\hline 0.7 & 182.3 \\
\hline 0.8 & 222.6 \\
\hline 0.9 & 262.9 \\
\hline
\end{tabular}

Table 2. Sensitivity analysis 